\begin{tabular}{|l|l|}
\hline ANC-1 & 1 \\
\hline
\end{tabular}

\title{
GEAR NOISE MEASURING TECHNIQUE
}

\author{
SH. ABDELAZIZ ${ }^{+} \quad$ N.GADALLAH ${ }^{++}$
}

\section{ABSTRACT}

The paper presents a part of work carried out for the Degree of $\mathrm{Ph} . \mathrm{D}$. on noise of gear of circular arc tooth profile.

For this purpose an anechoic room has been built in the Military Technical College to measure the variation of noise level of gears of circular arc tooth profile running at different speeds and transmitting different loads.

Overall noise levels were picked up by $1 / 2$ inch condenser microphone and recorded by tape recorder. The readings were then analysed and the largest frequency component were determined.

\section{INTRODUCTION}

Within the last fow years, concern increased about the pretection of the envirennent fron noire, as it was recognised that the toady rise in pellution cannot allowed to continue indefinitely.

The aim of noise measurement is to provide its objective physical measurements which can be compared with predetermined criteria to judge its acceptability. In order to ensure the qualio ty and uniformity of measurement results, the equipment specifications, measuring procedures and measuring sets are subjected to national and international standards[1].

+ Ph.D. Candidate, Machine Design Dept., Military Technical College, Cairo, EGYPT. ++ Lecturer, Machine Design Dept., Military Technical College, Cairo, EGYPT. 
\begin{tabular}{|l|l|}
\hline ANC-1 & 2 \\
\hline
\end{tabular}

$r$
SECOND A.M.E. CONFERENCE

6 - 8 May 1986 , Cairo

Although the noise level, its characteristics and the criteria used to assess it, differ from one environment to another, the methods of noise control are generally similar. Machinery noise is of different sources and types, and of complex nature. In order to overcome this difficulty, appropriate noise measuring method should be selected. Since the power spectrum is required for any comparative results to be meaningful; the engineering grade of accuracy ( ISO 3744 ) is quite sufficient. In that respect, anechoic rooms are efficient where sound power levels can be determined with reasonable accuracy. Satisfactory conditions can also be obtained in large rooms with sufficient sound absorptive material covering their walls, cieling and floors[2]. ANECHOIC ROOM

A double wall anechoic room is constructed for noise measurements. It represents a reflection-free space which is necessaryfor the determination of the directional properties of the radiated sound from the noise source. Room walls, ceiling and floor are covered with sound absorbing glass wool material which absorbs sound energy produced by and propagated radially from noise source. The room can be used for narrow band frequency analysis, also phase relations of acoustic energy from various source locations can be determined.

Construction :

A concrete foundation $(2.5 \times 2.5 \times 1 \mathrm{~m})$ is constructed at the room centre and is surrounded from all sides by double walls, as shown in Fig.(1). The gap between the foundation and the laboratory walls are filled up with wood dust and covered by wool glass to avoid vibration transfer to and from the out doors. The double wall consists of a sheet of compressed wood dust 16 mm thick covered on its internal surface with glass wool blankets $10 \mathrm{~cm}$ thick. Floor and internal ceiling surfaces are also covered with same sound absorbing material of the same thickness. 

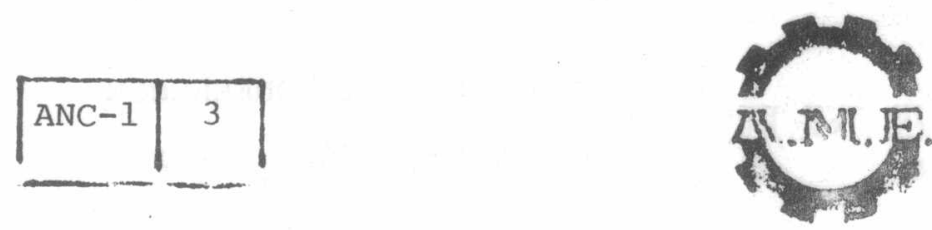

SECOND A.M.E. CONFERENCE

6 - 8 May 1986 , Cairo

$r$
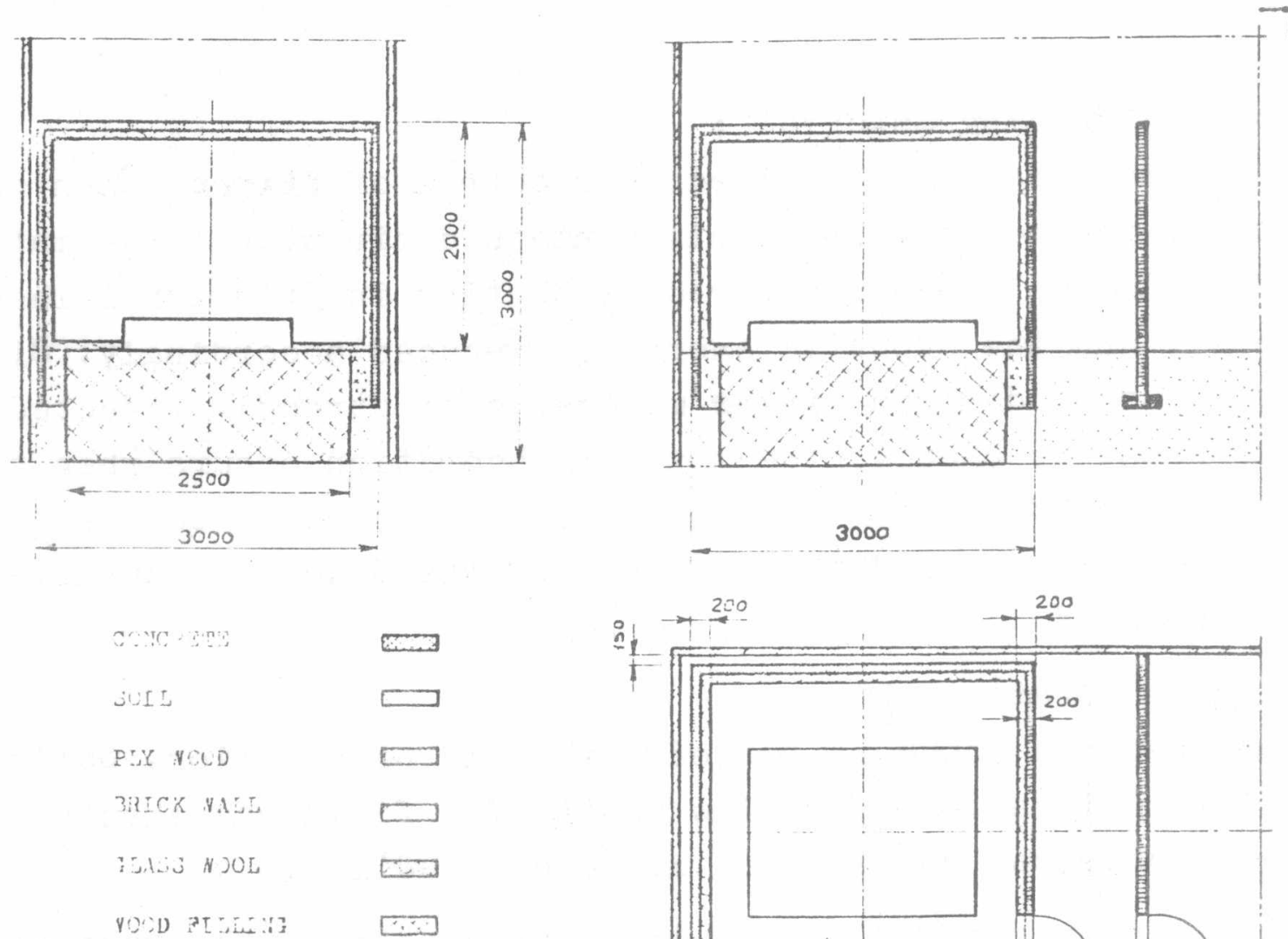

P1z. ( 1 ) \& The destzned dorblo wall inechols room
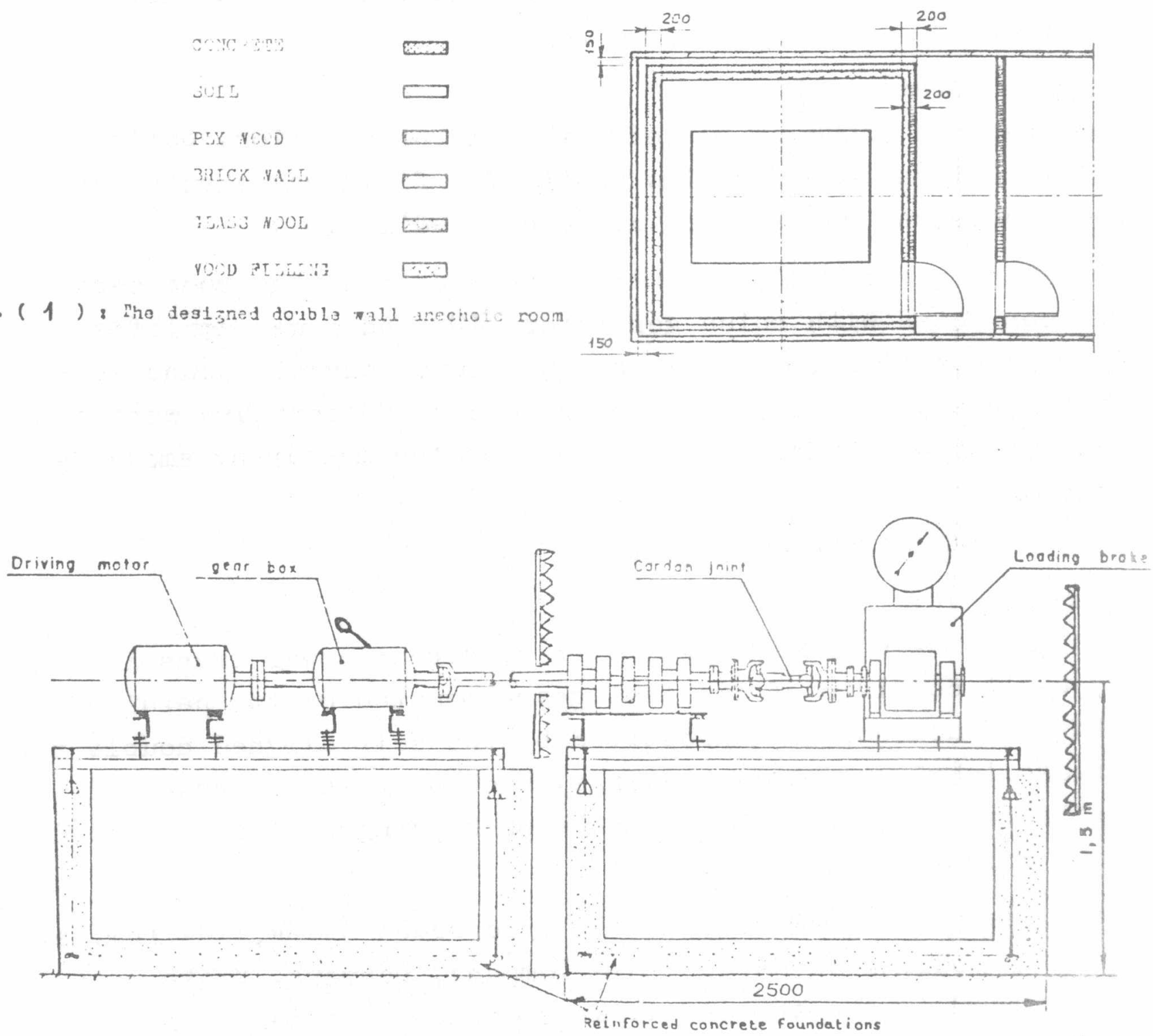

Fig. ( 2 ): Test rig scheme. 
Sound Absorbing Material :

Glass wool can be described as a matrix of fiber. When sound energy reaches the material, contained air within the matrix is " pumped " back and forth, resulting in frictional loss as heat, and the acoustic energy is reduced accordingly. Since motion of individual fiber molecules is strongly affected by the sound frequency, the maximum absorption occurs when the thickness of the absorptive material is about a quarter of the propagated wave length $(1 / 4 \lambda)$ of the lowest frequencies to be absorbed [3].

Room Calibration :

The anechoic room was tested for sound propagation. Satisfaction of inverse square law in the far field was checked on hemi spherical contours of different radii [3].

The isotropic sound source 4241 was placed at the room centre and connected with noise generator 1405 and power amplifier 2706 producing constant known sound level signal. Sound levels at different locations on the predetermined contours were picked up by microphone and read out on the measuring amplifier readings •

NOISE TESTING SET UP

Test Rig :

The test rig shown in Fig.(2) is of direct power transmission type. It consists of two test gears mounted on two parallel shafts. Each shaft is supported by two self aligned double row grease lubricated ball bearings. Each bearing is installed inside a seperate housing, and each housing is firmly bolted to a common steel plate.

Test gears are loaded by an electric brake $33 \mathrm{~kW}, 5000 \mathrm{rpm}$, and made by Zollner Electric Brake Company, Denmark. Brake rotor is coupled to the end of output shaft by a cardan joint. Loading of the brake is calibrated on a differential balance to indicate the load in $\mathrm{kgs} \pm 0.5 \%$ on its dial. Speed is indicated in rpm $\pm 1 \%$ on the tachometer dial of the electric brake instrument box driven by the output shaft. 
Each of test rig and electric brake is fastened, through two bolted channels, by four jacks for levelling, to the main rigid 2 tons cast iron grooved base. The latter is levelled and bolted to a concrete foundation at the anechoic room centre.

The microphone carrier, shown in Fig. (3), is placed around the test gears. It consists of a semi circular steel bridge of 30 $\mathrm{cm}$ radius and a wooden frame. The former is resting on two bracket bearings through short pins welded to the two frame's sides. The carrier could be angularly displaced and positioned at any angle with respect to the transverse plane of the test gears on a spherical surface $60 \mathrm{~cm}$ diameter centered at the mid point of the path of tooth contact. The microphone carrier couId also be axially displaced and adjusted with respect to the face width of gears.

Transmission Lay-Out :

Test gears are driven by three phase induction motor $12.5 \mathrm{HP}$, $50 \mathrm{~Hz}, 2900 \mathrm{rpm}$ and manufactured by English Electric Company, London, through a speed reduction gear box connected with rotor through a splined connection.
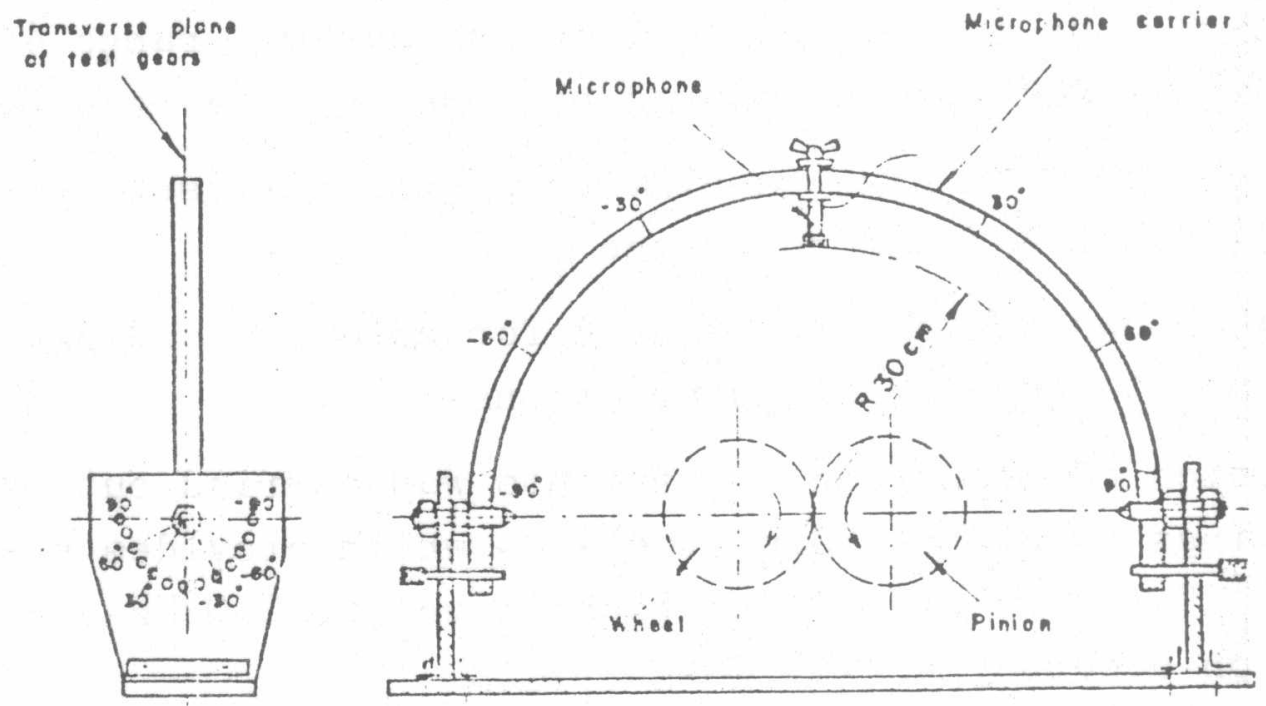

F:E. ( 3 ): Hicrophone carrier. 
The reduced speed is transmitted to the tested driver through a suitable propeller shaft coupled to the driver shaft through a universal joint, as shown in Fig.(2).

Both motor and gear reducer are rigidly mounted to another similar cast iron bed plate located outside the anechoic room and securely bolted on a concrete foundation.

Test Gears :

A pair of steel CirCarc gears of $8^{\prime \prime}$ normal diametral pitch was tested. Mid point of contact path was located at room centre. The design dimensions and specifications of the test gears are shown in Appendix I.

Measuring Instruments :

The gear noise is picked up by a ire inch B\&K condenser microphone cartridge type 4165 mounted to microphone preamplifier type 2619 of attenuation smaller than $0.03 \mathrm{~dB}$. The cartridge is protected against oil splashing by wind screen type UA0207. Noise is amplified by BớK audio frequency measuring amplifier type 2609 with frequency response $20 \mathrm{~Hz}$ to $20 \mathrm{KHz} \pm 0.5 \mathrm{~dB}$ and sensitivity in normal range $100 \mu \mathrm{V}$ to $30 \mathrm{~V}$ f.s.d. ( RMS ) and recorded by a portable 4 channel tape recorded type 7006, frequency range $0 \mathrm{~Hz}_{\mathrm{z}}$ to $12.5 \mathrm{KHz}_{\mathrm{Z}}-1 \mathrm{~dB}$ and dynamic range $44 \mathrm{~dB}$. Suitable input voltage is insured by power supply type ZG0199. Noise is analysed by high resolution signal analyser type 2033 and displayed on $X-Y$ recorder type 2308 .

Figure (4) shows the apparatus used for noise recording and : analysis and their electric connections.

Recalibration of measuring instruments was carried out every 10 recordings by pistonphone type 4220 which provides stable $124 \mathrm{~dB}( \pm 0.2 \mathrm{~dB})$ for $20 \mu \mathrm{Pa}$ sound level at $250 \mathrm{~Hz}$ and of calibration accuracy $\pm 0.15 \mathrm{~dB}$.

EXPE:RINLNTAL PROCEDURE AND RHSUIJTS

Procedure :

Gears are tested at running speeds of 500, 850, 1000 and 1450 $L^{r p m}$ and under transmitting loads of $15,30,60,90$ and $120 \mathrm{kp}$ g 


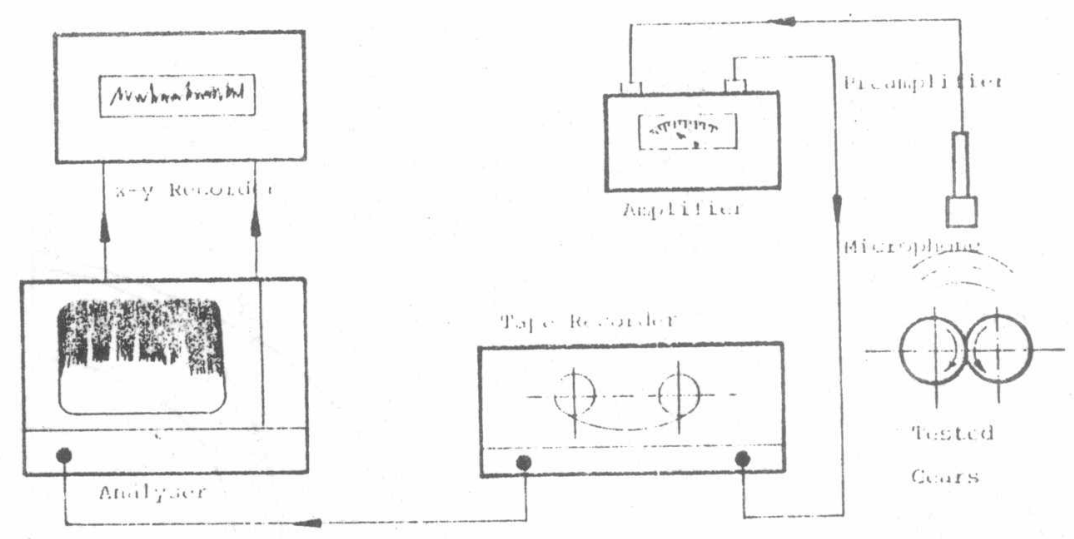

Noise was recorded at 7 observation points around the microphone carrier. This was repeated at five angular settings of $90^{\circ}$, $45^{\circ}, 0^{\circ},-45^{\circ}$ and $-90^{\circ}$ of the carrier, measured from the transverse plane of the test gears with the microphone carrier centered at the mid-point of the path of tooth contact.

In every test, overall gear noise pressure level was recorded for 20 seconds, and the measuring instruments were calibrated by the pistonphone after every ten tests.

All the noise recordings were then analysed at high resolution analyser and plotted by $\mathrm{X}-\mathrm{Y}$ recorder.

For every running condition, a three dimensional representation of noise distribution around the measuring acoustic hemi-sphere showed a clear image of the origin of the noise and ita propagation.

\section{Results :}

Figure (5) shows the noise distribution of 8 " NDP CirCarC gears in the gear transverse plane for different speeds under $60 \mathrm{kp}$ tangential load, while Fig.(6) shows the overall noise pattern in a plane inclined $45^{\circ}$ to transverse plane for different loads at speed $850 \mathrm{rpm}$.

Figures (7) and (8) show the noise distribution around the driving and driven gears, respectively, and the values given are the noise pressure levels in decibels when the gears are running at speeds of 500, 1000, and $1450 \mathrm{rpm}$ for the overall noise in different planes around each gear under $30 \mathrm{kp}$ tangential load. 

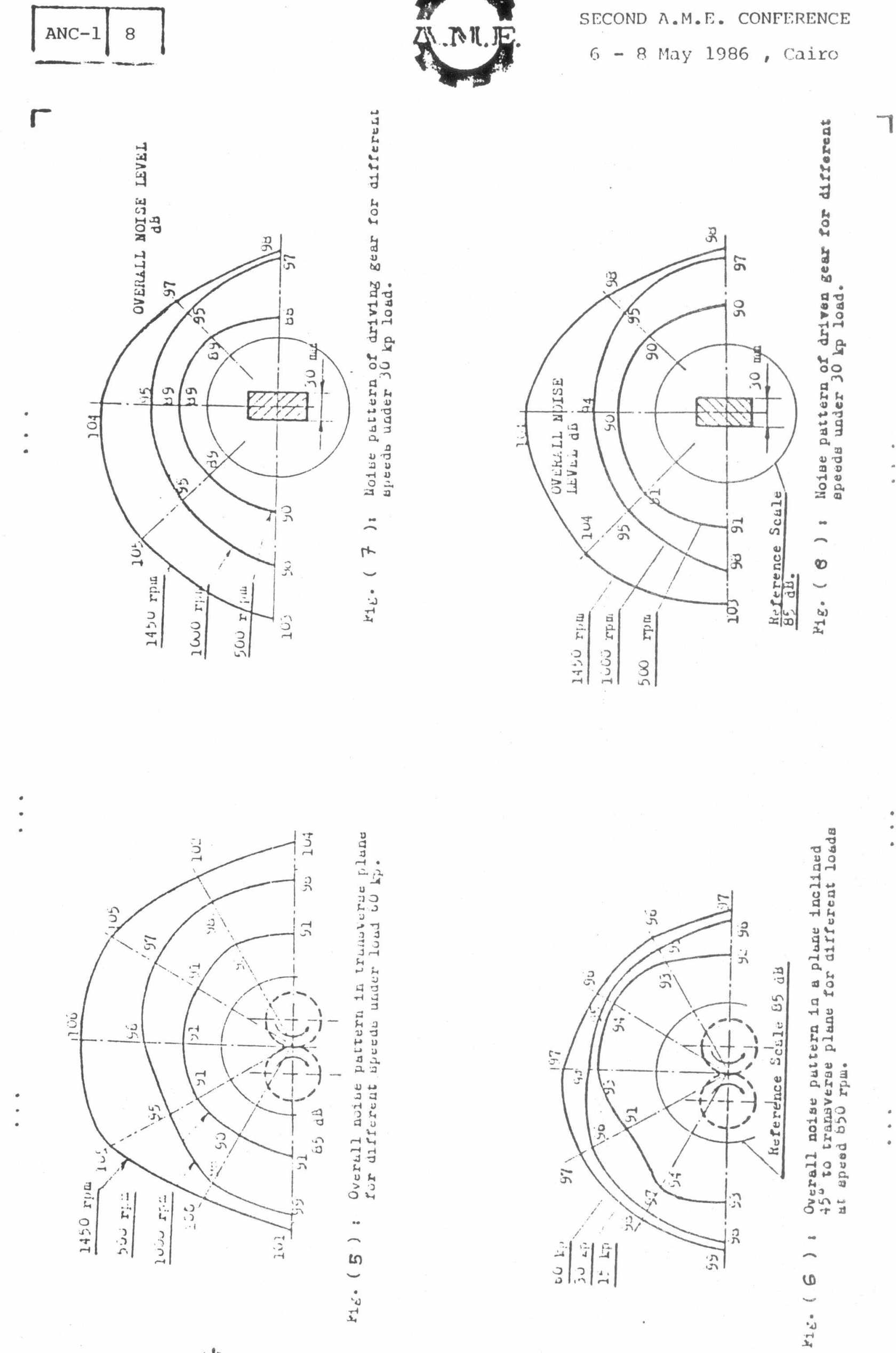

L

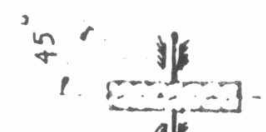




\begin{tabular}{|l|l|}
\hline ANC $^{-1}$ & 9 \\
\hline
\end{tabular}

$r$

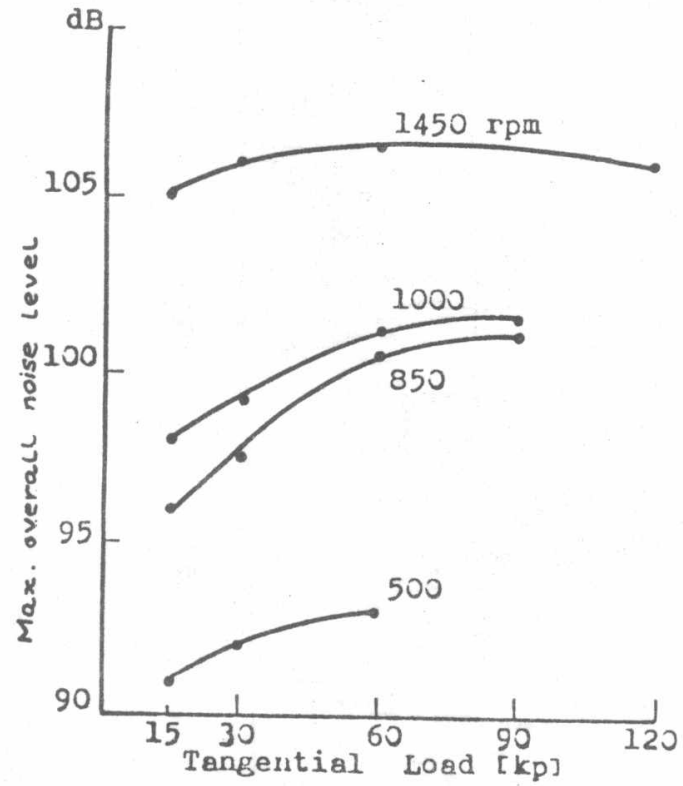

Fig. 9 : Change of overall noise level with transmitted load at diff. speeds.

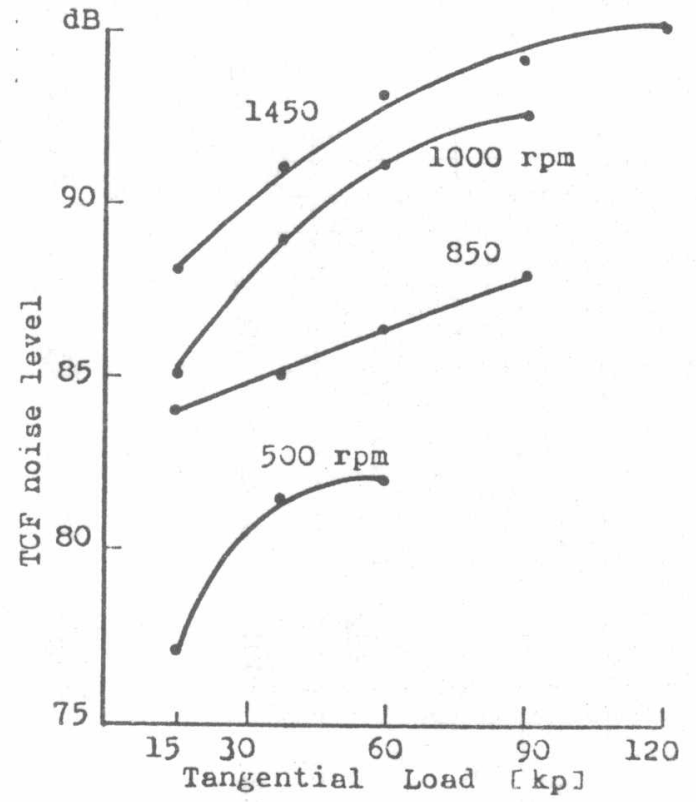

Fig. 10 : Change of noise level with load around TCF component.

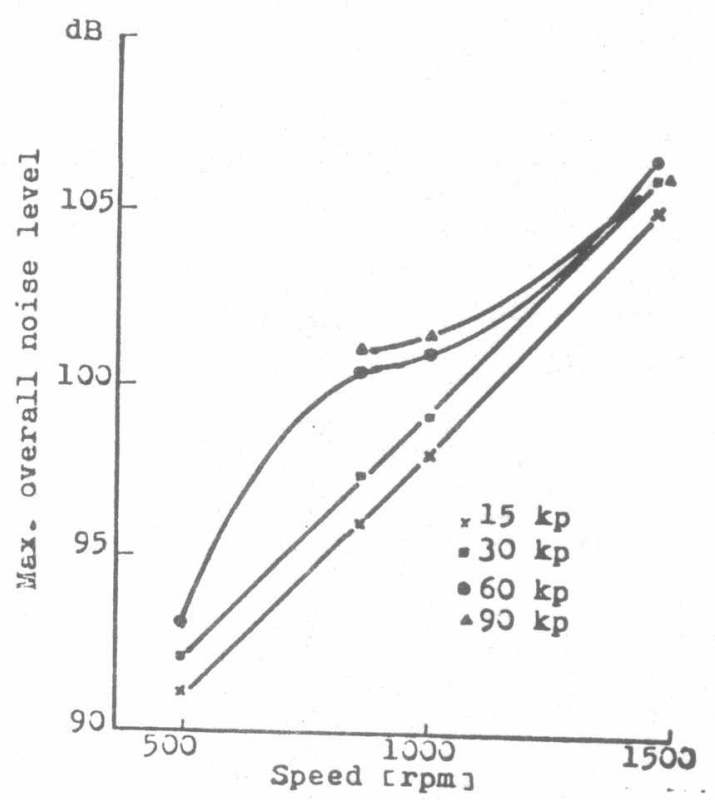

Fig. 11 : Change of overall noise with speed at different

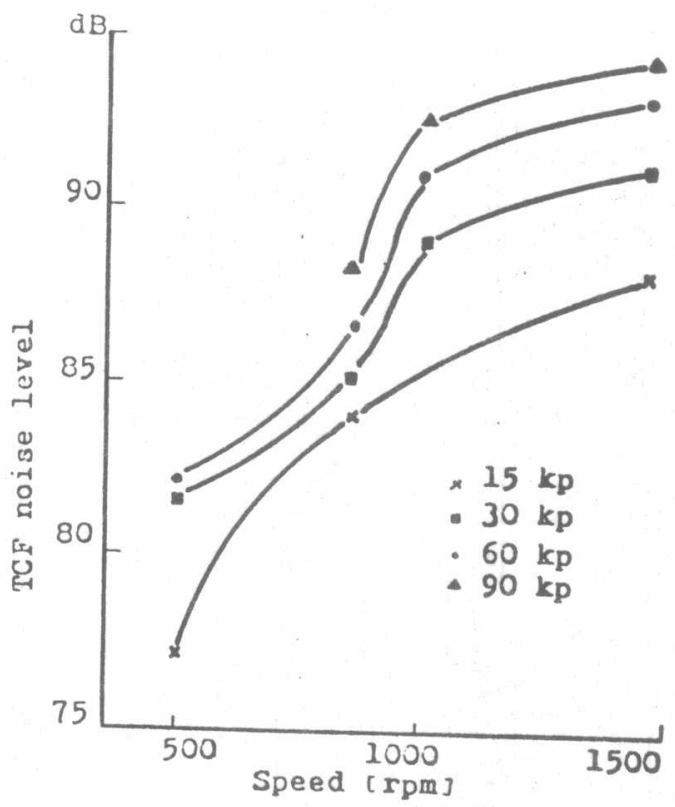

Fig. 12 : Change of noise level with speed around TCF component. 
\begin{tabular}{|l|l|}
\hline ANC-1 & 10 \\
\hline
\end{tabular}

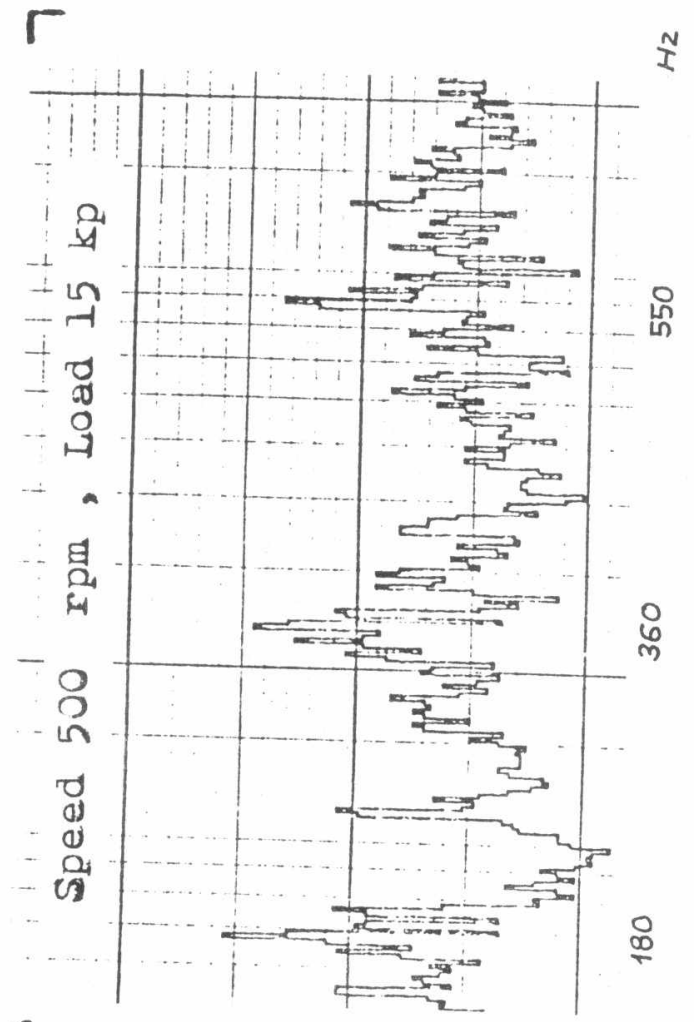

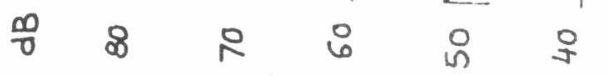
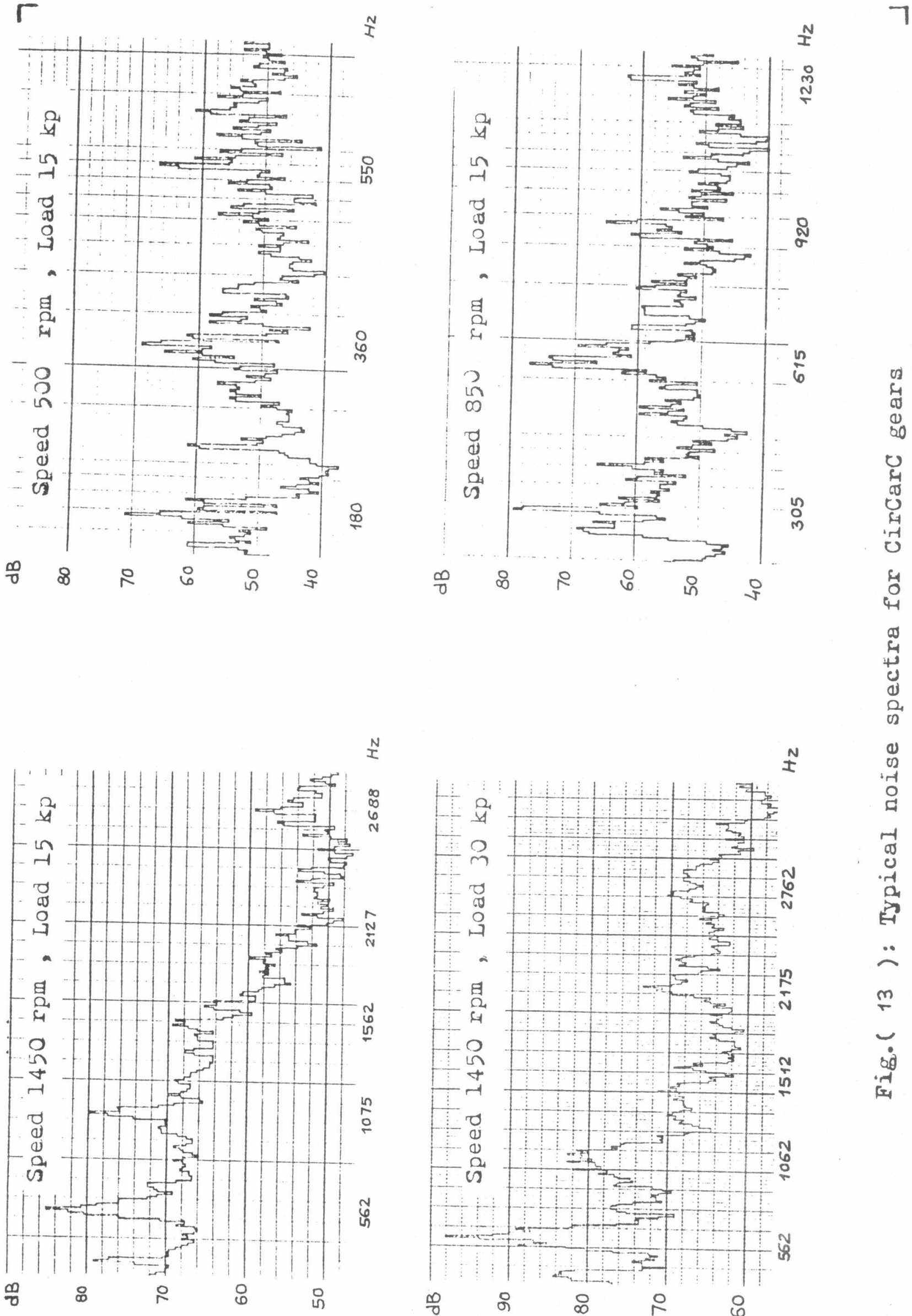

N

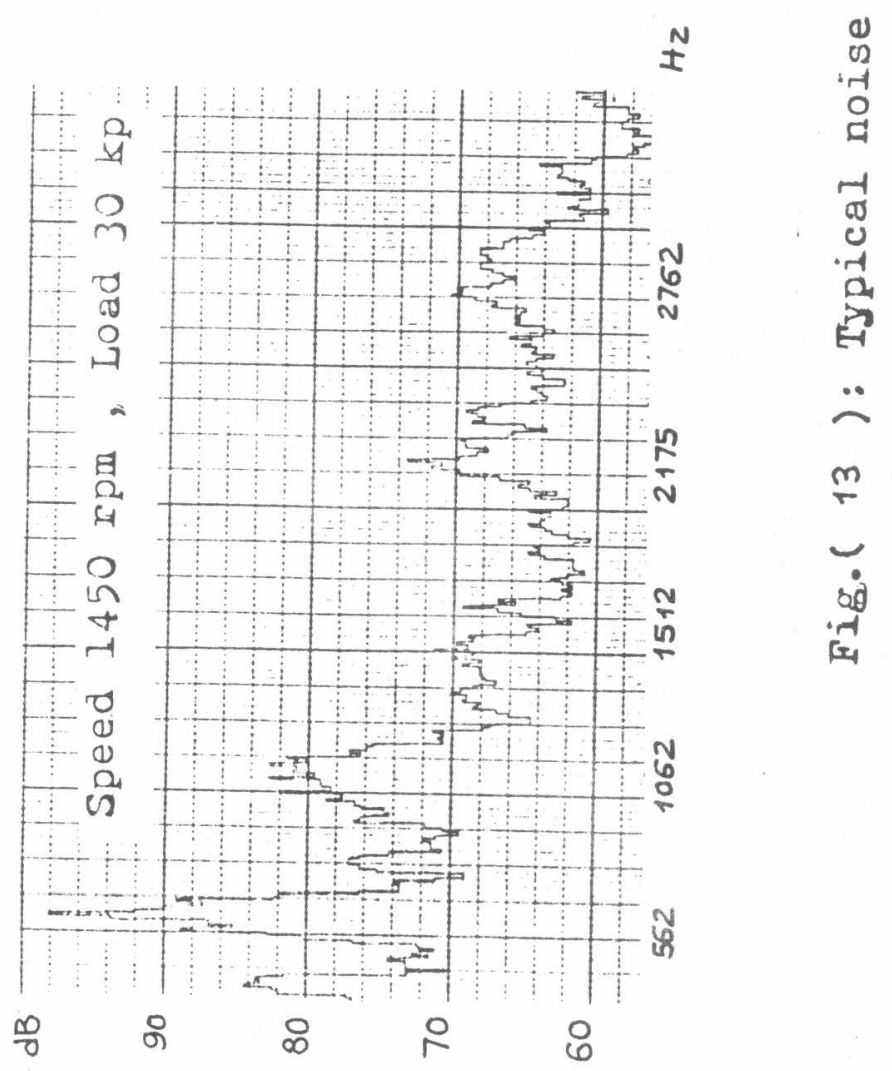


Figures (9) and (10) show the change of the total average overal1. noise level and the total average noise level at tooth contact frequency (TCF) component with the change of transmitted loads, respectively, at different speeds.

Figures (11) and (12) show the change of total average overall noise level and the total average noise level at TCF, respectively, with speeds at different loads.

Figure (13) represents a typical noise spectra for CirCarC gears of 8" NDP, measured on a real time analyser for different loads and speeds.

\section{CONCLUSIONS}

Calibration of the desiged and constructed anechoic room shows the validity of the inverse square law for measurements obtained on hemispherical contours of different radii. This result shows that the desiged anechoic room can be used for other noise measuring tests of different applications •

Obtained results show a good correspondance with results obtained in a similar anechoic room by Attia,A.Y. [4] for 6" and 8" NDP gears of Circular arc tooth profile.

\section{AC KNOWLEDGEMENTS}

The authors are greatly indebted to Professor Dr. Attia,A.Y., Ain Shams University, for his meticulous guidance and initiative ideas althrough the elaboration of the anechoic room. They also would like to thank Naj.Gen.Dr.H.T.Salem, MTC, for his generous help.

\section{REPERENCES}

[1] J.R.HASSALI, and K.ZAVERI, "Acoustic Noise Measurements " B\&K, 1979.

[2] M.DAVID LISCOMB, " Noise Control Handbook Of Principles And Fractices ", Von Nostrand Reinhold Enviromental Engineering Series, 1978. 
$\Gamma$

[3] F.Y.LYLE, " Sound Noise And Vibration Control ", Von Nostrand Reinhold Enviromental Engineering Series, 1978.

[4] A.Y.ATTIA, "Noise Of Gears Of Circular Arc Tooth Profile " J.Sound and Vib.(1970)11(4),pp.383-397.

APPENDIX I : SPECIFICALIONS OF CIRCAFC GEARS

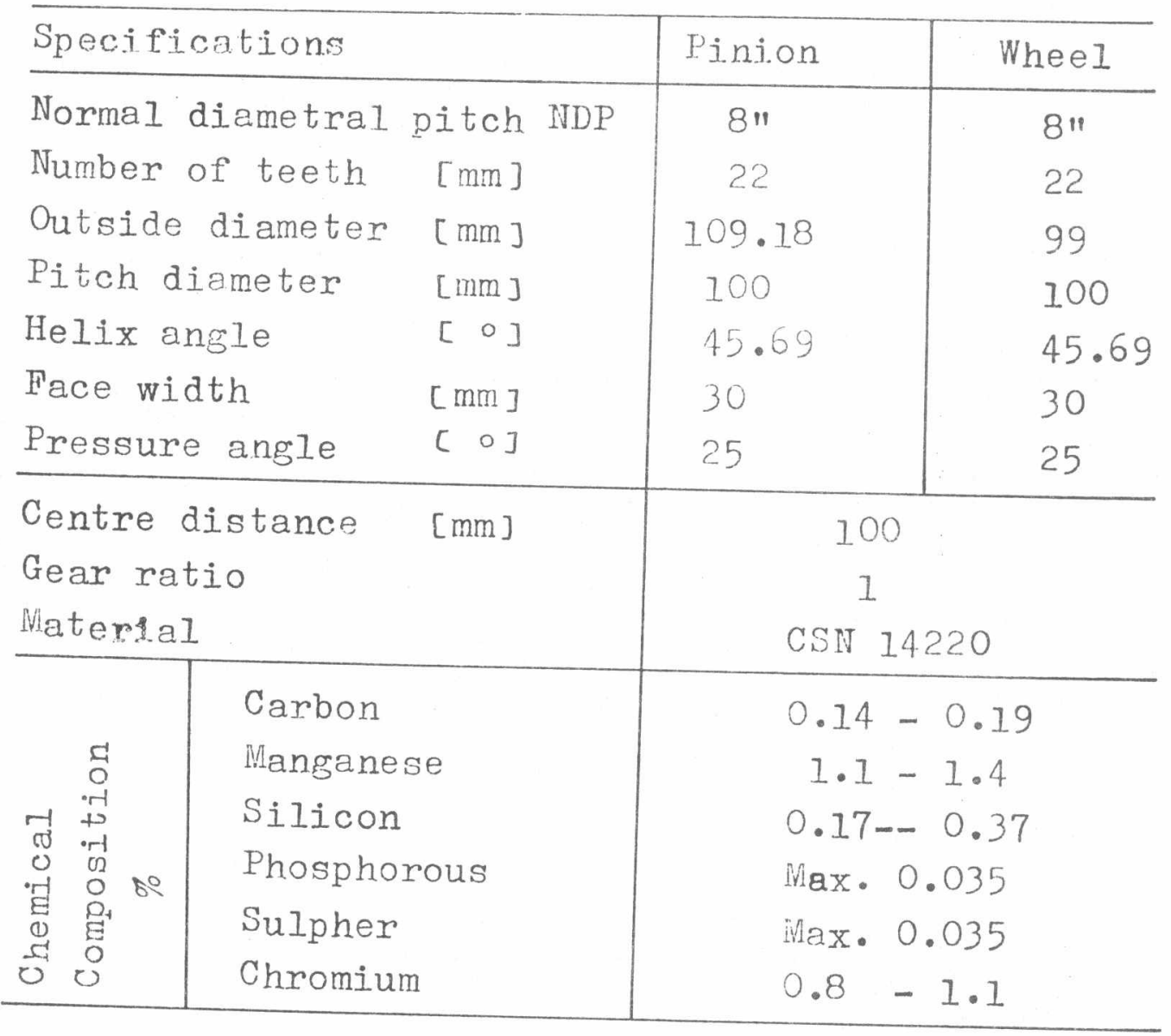

